\title{
Pressure- and 3D-derived coronary Flow Reserve with Hydrostatic Pressure Correction - A Validation by Intracoronary Doppler Measurements
}

\section{Balázs Tar}

Szabolcs-Sztamár-Bereg County Hospital

\section{András Ágoston}

Szabolcs-Szatmár-Bereg County Hospital

\section{Áron Üveges}

Szabolcs-Szatmár-Bereg County Hospital

\section{Gábor Tamás Szabó}

University of Debrecen: Debreceni Egyetem

\section{Tibor Szük}

University of Debrecen: Debreceni Egyetem

\section{András Komócsi}

University of Pecs Medical School: Pecsi Tudomanyegyetem Altalanos Orvostudomanyi Kar

\section{Dániel Czuriga}

University of Debrecen: Debreceni Egyetem

\section{Benjámin Csippa}

Budapest University of Technology and Economics: Budapesti Muszaki es Gazdasagtudomanyi Egyetem

\section{György Paál}

Budapest University of Technology and Economics: Budapesti Muszaki es Gazdasagtudomanyi Egyetem

\section{Zsolt Kőszegi ( $\nabla$ koszegi@med.unideb.hu )}

University of Debrecen: Debreceni Egyetem https://orcid.org/0000-0002-2817-6900

\section{Research Article}

Keywords: Stable angina, Fractional flow reserve (FFR), Coronary flow reserve (CFR), Quantitative coronary angiography, Coronary microvascular disease, Microvascular resistance reserve (MRR)

Posted Date: December 22nd, 2021

DOI: https://doi.org/10.21203/rs.3.rs-1181479/v1 
License: (c) (i) This work is licensed under a Creative Commons Attribution 4.0 International License. Read Full License 


\section{Pressure- and 3D-derived coronary flow reserve with hydrostatic pressure correction: a validation by intracoronary Doppler measurements}

*Balázs Tar $\mathrm{MD}^{2,3}$, András Ágoston $\mathrm{MD}^{2,3 *}$, Áron Üveges $\mathrm{MD}^{2,3}$, Gábor Tamás Szabó $\mathrm{MD}^{1,2}$, Tibor Szűk MD, $\mathrm{PhD}^{1,2}$, András Komócsi $\mathrm{MD}, \mathrm{PhD}^{4}$, Dániel Czuriga $\mathrm{MD}, \mathrm{PhD}^{1,2}$, Benjámin Csippa MSc ${ }^{5}$, György Paál PhD ${ }^{5}$, Zsolt Köszegi MD, $\mathrm{PhD}^{1-3}$

${ }^{1}$ Institute of Cardiology, University of Debrecen, Debrecen, Hungary

${ }^{2}$ University of Debrecen, Kálmán Laki Doctoral School of Biomedical and Clinical Sciences, Debrecen, Hungary

${ }^{3}$ Szabolcs - Szatmár - Bereg County Hospitals and University Teaching Hospital, Nyíregyháza, Hungary

${ }^{4}$ Heart Institute, Medical School, Pécs, Hungary

${ }^{5}$ Department of Hydrodynamic Systems, Budapest University of Technology and Economics, Budapest, Hungary

*These authors equally contributed to this work.

Short title: Pressure and 3D-derived coronary flow reserve

\section{Corresponding author:}

Zsolt Kőszegi, M.D., Ph.D.

Institute of Cardiology, University of Debrecen

Móricz Zs. krt. 22, H-4032 Debrecen, Hungary

Tel./Fax: +36 52 255928; E-mail: koszegi@med.unideb.hu 


\begin{abstract}
Purpose: To develop a method of coronary flow reserve (CFR) calculation derived from threedimensional (3D) coronary angiographic parameters and intracoronary pressure data during fractional flow reserve (FFR) measurement.
\end{abstract}

Methods: Altogether 19 coronary arteries of 16 native and 3 stented vessels were reconstructed in 3D. The measured distal intracoronary pressures were corrected to the hydrostatic pressure based on the height differences between the levels of the vessel orifice and the sensor position. Classical fluid dynamic equations were applied to calculate the flow during the resting state and vasodilatation on the basis of morphological data and intracoronary pressure values. 3D-derived coronary flow reserve $\left(\mathrm{CFR}_{\mathrm{p}-3 \mathrm{D}}\right)$ was defined as the ratio between the calculated hyperemic and the resting flow and was compared to the CFR values simultaneously measured by the Doppler sensor (CFR Doppler $_{\text {. }}$

\title{
Results
}

Haemodynamic calculations using the distal coronary pressures corrected for hydrostatic pressures showed a strong correlation between the individual $\mathrm{CFR}_{\mathrm{p}-3 \mathrm{D}}$ values and the $\mathrm{CFR}_{\text {Doppler }}$ measurements $(r=0.89, \mathrm{p}<0.0001)$. Hydrostatic pressure correction increased the specificity of the method from $46.1 \%$ to $92.3 \%$ for predicting an abnormal CFR Doppler $_{2}$.

Conclusions: $\mathrm{CFR}_{\mathrm{p}-3 \mathrm{D}}$ calculation with hydrostatic pressure correction during FFR measurement facilitates a comprehensive haemodynamic assessment, supporting the complex evaluation of macro- and microvascular coronary artery disease. 


\section{Key words}

Stable angina; Fractional flow reserve (FFR); Coronary flow reserve (CFR), Quantitative coronary angiography; Coronary microvascular disease, Microvascular resistance reserve (MRR)

\section{Abbreviations}

APV average peak velocity at rest or during vasodilatation (vd) measured by Doppler wire

CFR coronary flow reserve

LCX left circumflex coronary artery

f friction-related pressure loss coefficient

FFR fractional flow reserve

LAD left anterior descending coronary artery

MLA minimum lumen area

MRR microvascular resistance reserve

OM obtuse marginal branch

Pd corr: corrected distal coronary pressure for hydrostatic pressure

$\mathbf{P d} / \mathbf{P a}$ ratio of distal to aortic coronary pressure

Q calculated volumetric flow

RCA right coronary artery

$\mathbf{R} \boldsymbol{\mu}$ resistance of the microvasculature

$\Delta \mathbf{P}$ hyrostatic pressure hydrostatic offset 


\section{Introduction}

According to the current European guideline on coronary revascularization, pressure wire-derived fractional flow reserve (FFR) measurement is recommended for the functional assessment of lesion severity in patients with $40-90 \%$ diameter stenosis and without prior evidence of ischemia [1]. A more recent guideline suggests the consideration of a guidewire-based coronary flow reserve CFR measurement in patients with persistent symptoms but with preserved FFR [2] based on earlier publications [3-5]. The combination of FFR and CFR evaluation may identify the potential components of ischemia originating from the decreased conductance of the epicardial vessels and the increased resistance of the microvasculature [6-9].

As a temperature sensor, the pressure-wire sensor makes it possible to calculate thermodilution, however, this method comes with several limitations, as already detailed in early validation studies [10-12]. On the other hand, the direct measurement of coronary flow velocity by a Doppler sensor is considered technically difficult to perform; consequently, it is not routinely used in clinical practice.

The resistance of the microvasculature $(\mathrm{R} \mu)$ is defined as the ratio of the distal coronary pressure divided by the distal coronary flow rate. During bolus thermodilution measurements, the resistive reserve ratio was calculated as the index expressing the ratio between hyperemic and basal microcirculation [13]. Lately, the term microvascular resistance reserve (MRR) was suggested for the same index during continuous thermodilution technique [14] and Doppler measurements [15]. MMR is calculated as the ratio of $\mathrm{R} \mu$ at rest and $\mathrm{R} \mu$ during hyperemia.

In our study, we aimed at developing a clinically applicable method for calculating specific CFR and MRR values $\left(\mathrm{CFR}_{\mathrm{p}-3 \mathrm{D}}\right.$ and $\left.\mathrm{MRR}_{\mathrm{p}-3 \mathrm{D}}\right)$ during FFR measurement, using simple hemodynamic 
calculations that combine intracoronary pressure data and 3D anatomical parameters (Figure 1). The results of our calculations were compared to data obtained using invasive Doppler wire measurement, as a gold standard of flow assessment.

It has recently been underlined that pressure differences are systematically detectable between the different segments of the coronary arteries in the supine position [16-18]. We also investigated how the correction of distal pressure for hydrostatic pressure offset affects the pressure-derived flow determination.

\section{Methods}

\section{Patient inclusion criteria}

Patients, who underwent clinically indicated invasive physiological investigations, were selected for this study, with a single stenosis of intermediate severity (40-80\% based on visual assessment) in a main branch of the epicardial coronary artery system. Cases with good quality hyperemic and resting pressure and Doppler traces were included for the evaluations. Only traces without pressure drift $(<1 \mathrm{mmHg}$ ) confirmed by the pullback of the pressure sensor at the end of the procedure were considered. Patients with an acute coronary syndrome, left main stenosis, ostial stenosis, earlier bypass surgery or diffuse coronary artery disease were excluded. The study has been approved by the local ethics committee of the University of Debrecen and has therefore been performed in concordance with the Declaration of Helsinki.

Invasive coronary angiography and simultaneous pressure and flow measurement by ComboWire 
After administering 5000 international units (IU) of intravenous, unfractionated heparin (UFH) and intracoronary glyceryl trinitrate (GTN), diagnostic angiographic cine-recordings were acquired from standard projections, using a digital X-ray equipment (Axiom Artis, Siemens). Diagnostic angiographic images were recorded at 15 frames per second. Low- or iso-osmolar contrast material (CM) (iopamidol [Scanlux] or iodixanol [Visipaque]) was injected in $5 \mathrm{~mL}$ fractions with a speed of $3 \mathrm{~mL} / \mathrm{sec}$ using a dedicated contrast pump (ACIST CVi ${ }^{\mathrm{TM}}$, ACIST Medical Systems). If the operator detected a 40-80\% diameter stenosis by visual assessment, complete physiological measurements were performed via a $6 \mathrm{~F}$ guiding catheter, using a ComboWire equipped with both pressure and Doppler sensors (Philips Volcano, San Diego, CA, USA).

After the pressures were equalized with the sensor positioned at the level of the catheter tip, it was advanced through the coronary artery stenosis, and measurements were performed approximately $2 \mathrm{~cm}$ distal to the lesion. Following the basal pressure and flow measurements, $150-200 \mu \mathrm{g}$ intracoronary adenosine was administered, and the pressure and Doppler traces were recorded. One representative measurement is presented in Figure 2.

\section{Three-dimensional quantitative coronary artery reconstruction and hemodynamic calculations}

Offline 3D angiographic reconstruction was performed from two selected angiograms of good quality, with an at least $25^{\circ}$ difference in angle, using dedicated software (QAngio XA Research Edition 1.0, Medis Specials bv, Leiden). The reconstructed vessel segment was marked from the coronary orifice to the location of the wire sensors. Numerous geometric measures describing the lesion (average cross-sectional diameters and vessel segment lengths), as well as the proximally and distally connecting vessel segments were automatically obtained by the software. These values 
with intracoronary pressure at the proximal and distal positions during the resting and vasodilation states were combined for hemodynamic calculations. The method and its validation are described in our previous papers in detail $[19,20]$.

\section{Calculation of the $M R R_{p-3 D}$}

The resistance of the microvascular system is the ratio of the distal coronary pressure (Pd) divided by distal coronary flow $(\mathrm{Q})$ during resting condition and hyperemia. The ratio of the resting and hyperemic resistance gives us the microvascular resistance reserve (MRR):

$$
M R R=\frac{P d_{\text {resting }} / Q_{p-3 D} \text { resting }}{P d_{\text {hyperemic }} / Q_{p-3 D} \text { hyperemic }}
$$

Correction of the distal coronary pressure for hydrostatic pressure

In supine position, the measured pressure difference between the catheter tip and the pressure sensor distal to the lesion originates from two components, namely the pressure loss caused by the flow through the stenosis, and the difference between the hydrostatic pressure at the catheter tip at the coronary orifice and the level of the distal intracoronary sensor (Figure 3).

The latter component can be referred as hydrostatic offset ( $\left.\Delta \mathrm{P}_{\text {hyrostatic pressure }}\right)$, and can modify the detected pressure ratio values through the "altered" distal pressure value [16-18].

The correction of distal pressure for hydrostatic pressure $\left(\mathrm{Pd}_{\text {corr }}\right)$ was based on the height differences between the orifice and other coronary artery segments in supine positions. The distal pressure values were corrected, using a correction factor of $0.77 \mathrm{mmHg}$ hydrostatic pressure per $1 \mathrm{~cm}$ height difference, where blood density was taken as $1050 \mathrm{~kg} / \mathrm{m}^{3}$ (Figure 3): 
$\mathrm{Pd}$ corr $=\mathrm{Pd}-\Delta \mathrm{P}_{\text {hyrostatic pressure }}$

\section{Statistical analysis}

Statistical evaluations were performed in MedCalc Statistical Software, Version 14.8.1 (MedCalc Software bvba, Ostend, Belgium). Following a normality test, Spearman's correlation analysis was carried out. The correlation between $\mathrm{CFR}_{\mathrm{p}-3 \mathrm{D}}$ and the $\mathrm{CFR}_{\text {Doppler }}$ was examined both without and with hydrostatic pressure correction of the distal pressure. Agreement between $\mathrm{CFR}_{\text {Doppler }}$ and CFR $\mathrm{p}_{\mathrm{p}}$ 3D was assessed using the Bland-Altman analysis. The area under the curve (AUC) calculated by receiver operating characteristic analysis was applied to determine the diagnostic power of $\mathrm{CFR}_{\mathrm{p}-3 \mathrm{D}}$ without and with hydrostatic pressure correction. Sensitivity and specificity of $\mathrm{CFR}_{\mathrm{p}-3 \mathrm{D}}$ without and with hydrostatic pressure correction were calculated using the standard method.

\section{Results}

We performed simultaneous intracoronary pressure and Doppler measurement by ComboWire in 20 patients screened in the study. In 3 cases the Doppler signal quality was insufficient for the calculation, in 1 further case more than $2 \mathrm{mmHg}$ drift was detected at the end of the investigation and the attempt for repeat measurement was also failed. Therefore, sixteen 16 patients (14 males, 2 females) with single, intermediate epicardial coronary stenosis were involved in the study. In 3 cases, measurements were performed both before and after stent implantation.

Patient characteristics are presented in Table 1. The results of 3D reconstruction and the measured physiological data are summarized for each interrogated vessel in Table 2. 
Correlation and agreement between the results of the $C F R_{\text {Doppler }}$ measurements and calculated $C_{F} R_{p-3 D}$ values without and with the correction for hydrostatic offset

When including morphological data from 3D coronary angiography in the hemodynamic calculation and correcting the values for hydrostatic pressure, a strong correlation was found between the individual $\mathrm{CFR}_{\mathrm{p}-3 \mathrm{D}}$ values and the $\mathrm{CFR}_{\text {Doppler }}$ measurements $(\mathrm{r}=0.89, \mathrm{p}<0.0001)$. A weak, but still significant correlation was demonstrated even without the correction of hydrostatic error $(\mathrm{r}=0.57$, $\mathrm{p}=0.01)$ Figure 4 A-B. The difference between the two correlations was found to be significant $(\mathrm{p}=0.02)$.

The Bland-Altman analysis showed the mean differences between the Doppler-measured and the calculated CFR $_{\mathrm{p}-3 \mathrm{D}}$ values with and without hydrostatic offset correction to be $-0.02( \pm 1.96 \mathrm{SD}$ : $0.47,-0.50)$ and $-0.05( \pm 1.96 \mathrm{SD}: 1.38,-1.48)$, respectively. After hydrostatic offset correction, the values of $\mathrm{CFR}_{\mathrm{p}-3 \mathrm{D}}$ and those of $\mathrm{CFR}_{\text {Doppler }}$ got closer without any systematic skewing suggesting a higher level of concordance Figure 4 C-D).

Correlation and agreement between the results of the ComboWire based MRR measurements $\left(M R R_{\text {Combowire }}\right)$ and the calculated $M R R_{p-3 D}$ values with the correction for hydrostatic offset

The calculated microvascular resistance reserve $\left(M R R_{p-3 D}\right)$ also demonstrated a good correlation

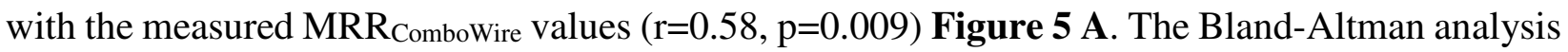
showed the mean differences between the Doppler-measured and the calculated $\mathrm{MRR}_{\mathrm{p}-3 \mathrm{D}}$ values with hydrostatic offset correction to be $-0.3( \pm 1.96 \mathrm{SD}: 1.5,-2.2)$ with a trend of higher differences 
at higher MRR values. It was found that the $\mathrm{MRR}_{\mathrm{p}-3 \mathrm{D}}$ values were systematically overestimated

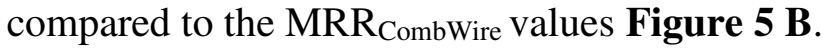

The results of hydrostatic offset correction on the pressure ratios and on the $C F R_{p-3 D}$ in the main coronary branches

Figure 6 shows the clustered multiple variable graphs of resting $\mathrm{P}_{\mathrm{d}} / \mathrm{P}_{\mathrm{a}}(\mathbf{A}), \mathrm{FFR}(\mathbf{B})$, and the $C F R_{\mathrm{p}-}$ 3D (C) without and with hydrostatic pressure correction. In line with the findings of our previous work [18], the correction of the hydrostatic offset resulted in specific concordant differences between the uncorrected and corrected values in the main coronary branches in both resting and hyperemic (FFR) states (Figure 6 A and B). The correction definitively increased the values in the LAD, while in the LCx and the RCA, the values decreased. We observed much higher differences in CFRs, especially in the range of higher CFR values (Figure 6 C).

Diagnostic powers of $C F R_{p-3 D}$ calculated from the distal pressure without and with hydrostatic offset correction for identifying $C F R_{\text {Doppler }}<2$

The diagnostic power of different computations of the $\mathrm{CFR}_{\mathrm{p}-3 \mathrm{D}}$ for predicting the abnormal $\mathrm{CFR}_{\text {Doppler }}$ was assessed using the computed $\mathrm{CFR}_{\mathrm{p}-3 \mathrm{D}}$ (cut-off value=2). The AUCs of the values calculated without and with hydrostatic error correction were 0.73 (CI: 0.48-0.90) and 0.96 (CI: 0.78-1.00), respectively. Correcting for hydrostatic pressure offset increased the specificity of the method from $46.1 \%$ to $92.3 \%$, while the sensitivity of both calculations was $100 \%$. 


\section{Discussion}

In a pioneering research, the pressure drop across an arterial stenosis was estimated satisfactorily by simple flow equations [21]. Later the 3D anatomical characteristics of the coronary artery were also incorporated into computational fluid dynamics calculations leading to the virtual, image based FFR assessment [22-24]. Recently, the possibility to determine coronary flow from invasively measured intracoronary pressure has been arisen by "backward" calculations $[25,26]$. The so-called pressure-bounded coronary flow reserve (CFRpb) assessment identified the possible range of CFR according to the resting and hyperemic pressures.

Wijntjens and colleagues compared the $\mathrm{CFR}_{\mathrm{pb}}$ to flow-derived CFR defined by thermodilution and Doppler measurements in 453 intermediate coronary lesions, but they found a poor diagnostic agreement between the two estimations [27]. It is important to emphasize, that in this publications, hydrostatic offset correction of the distal coronary pressure was not applied to CFR calculations.

Similar to the method presented in this article, an absolute flow calculation with fluid dynamic computation (CFD) using the Ansys software (Q $\mathrm{Q}_{\mathrm{CFD}}$ ) was recently published by Morris et al [28]. In contrast with our method where the distal flow is rendered to the tapered vessel size [19], their in vitro and in vivo models, did not account for flow to side branches, resulting in underestimation of the volumetric flow [29]. This underestimation could lead to unlikely low resting and hyperemic calculated flow values in major coronary branches, as was pointed out in the editorial responding to their paper [30]. It is very obvious that in their in vivo study the hydrostatic pressure error had caused at least partly the very week correlation to the Doppler results.

The direction of the effect of the hydrostatic offset depends on the orientation of the sensor in the distal position relative to the coronary orifice. 
If one interrogates distal LAD with the sensor, the hydrostatic pressure is lower in supine position, which results in higher pressure ratios after hydrostatic offset correction. In contrast, LCx takes a downward course, which leads to higher hydrostatic pressure at the level of the sensor, and consequently the pressure values are lower compared to the measured one following correction. The height correction of RCA measurements can result a slight increase of the distal pressure value, as the distal sensor in the distal RCA is at a lower level compared to the orifice (Figure $6 \mathbf{A}$ and B) [18]. Thus, a slight increase in the corrected pressure ratios can be observed (Figure $6 \mathbf{A}$ and B).

In our opinion, the correction of distal pressure for hydrostatic pressure is essential when determining pressure-derived CFR. A minor hydrostatic pressure may have a significant influence on the measured pressure gradient, especially in resting state.

This phenomenon is demonstrated in Figure 6C, where the correction resulted in significant differences between the calculated $\mathrm{CFR}_{\mathrm{p}-3 \mathrm{D}}$ and the uncorrected values, most prominently in the range of higher CFR values.

The weCFR $\mathrm{p}_{\mathrm{p}-3 \mathrm{D}}$ values calculated after the correction for hydrostatic pressure and those derived from native pressure values were compared with the Doppler flow measurements. A strong correlation was demonstrated between the individual $\mathrm{CFR}_{\mathrm{p}-3 \mathrm{D}}$ and the $\mathrm{CFR}_{\text {Doppler }}$ values when the correction for hydrostatic pressure was made, while only week correlation was found without hydrostatic pressure correction.

Importantly, the elimination of hydrostatic pressure offset increased the specificity of our method from $46.1 \%$ to $92.3 \%$, while the sensitivity of both calculations remained $100 \%$ against the "gold standard" Doppler measurement. 


\section{Limitations of the study}

The main limitation of our pilot study of $\mathrm{CFR}_{\mathrm{p}-3 \mathrm{D}}$ calculations is represented by the small sample size. However, the archived and statistically highly significant results look promising.

We are aware that our simple model considers only Hagen-Poiseuille-type friction losses and highly simplified Borda-Carnot type separation losses. For this reason, the calculation of the flow rate is also not expected to be always accurate, but because the CFR is by definition a ratio-type parameter, the $\mathrm{CFR}_{\mathrm{p}-3 \mathrm{D}}$ may be accurate enough for clinical applications [20].

The simplified haemodynamic model used for the calculation of the $\mathrm{CFR}_{\mathrm{p}-3 \mathrm{D}}$ is able to consider only one stenosis, with a normal proximal and distal segments. Consequently, our flow calculation method in the present form may not be adequate for assessing the hemodynamic relevance of sequential stenoses.

In cases with a very low resting pressure gradient, any small error during the measurement could potentially cause a great deviation in the results, as these values are represented in the denominator during the calculations. However, most of the cases with intermediate coronary lesions showed not less than a 1-2 mmHg resting pressure gradient, which allowed the appropriate calculation of the $\mathrm{CFR}_{\mathrm{p}-3 \mathrm{D} \text {. }}$

\section{Conclusions}

In this study, we proposed a method of combined determination of FFR and CFR without the need for Doppler wire or thermodilution procedure. In our opinion, the $\mathrm{CFR}_{\mathrm{p}-3 \mathrm{D}}$ is applicable for any 
coronary angiography with the clinically indicated invasive measurement of the FFR, when the target vessel is suitable for 3D reconstruction. The flow calculation does not require significantly more time this way. We have created an online calculation tool (http://coronart.unideb.hu/) available, which enables a more comprehensive assessment of coronary physiology than FFR measurement alone. As a result, the consequences of an epicardial stenosis can be assessed simultaneously with the state of the microvasculature, thereby supporting the clinical decision for selecting the most appropriate therapy. In our opinion, large-scale studies are warranted to investigate the clinical relevance of the pressure-flow relation determined by our technique [31].

\section{Declarations}

\section{Ethics approval}

The study was conducted in accordance with the Declaration of Helsinki and its later amendments or comparable ethical standards. Informed consent was obtained from all individual participants included in the study.

\section{Funding}

The University of Debrecen supported this work in the framework of a proof-of-concept project (PoC 007).

Á. Ü. was supported by the ÚNKP-20-03 new national excellence program of the Ministry for Innovation and Technology from source of the National Research, Development and Innovation Fund (Hungary).

\section{Conflicts of interest}


The authors declare that they have no conflict of interest in the subject matter or materials discussed in this manuscript. The patent of the method detailed in this paper has been issued by the European Patent Office (WO2019175612, applicant: University of Debrecen, inventor: Z.K.).

\section{Availability of data and material}

The data that supports the findings of this study are available in the supplementary material of this article.

\section{References}

1. Neumann FJ, Sousa-Uva M, Ahlsson A, Alfonso F, Banning AP, Benedetto U, Byrne RA, Collet JP, Falk V, Head SJ et al: 2018 ESC/EACTS Guidelines on myocardial revascularization. European Heart Journal 2019, 40(2):87-165.

2. Knuuti J, Wijns W, Saraste A, Capodanno D, Barbato E, Funck-Brentano C, Prescott E, Storey RF, Deaton C, Cuisset T et al: 2019 ESC Guidelines for the diagnosis and management of chronic coronary syndromes. European Heart Journal 2020, 41(3):407477.

3. Sara JD, Widmer RJ, Matsuzawa Y, Lennon RJ, Lerman LO, Lerman A: Prevalence of Coronary Microvascular Dysfunction Among Patients With Chest Pain and Nonobstructive Coronary Artery Disease. JACC Cardiovasc Interv 2015, 8(11):1445-1453. 
4. Lee BK, Lim HS, Fearon WF, Yong AS, Yamada R, Tanaka S, Lee DP, Yeung AC, Tremmel JA: Invasive evaluation of patients with angina in the absence of obstructive coronary artery disease. Circulation 2015, 131(12):1054-1060.

5. Ford TJ, Stanley B, Good R, Rocchiccioli P, McEntegart M, Watkins S, Eteiba H, Shaukat A, Lindsay M, Robertson K et al: Stratified Medical Therapy Using Invasive Coronary Function Testing in Angina: The CorMicA Trial. J Am Coll Cardiol 2018, 72(23 Pt A):2841-2855.

6. Petraco R, van de Hoef TP, Nijjer S, Sen S, van Lavieren MA, Foale RA, Meuwissen M, Broyd C, Echavarria-Pinto M, Foin N et al: Baseline instantaneous wave-free ratio as a pressure-only estimation of underlying coronary flow reserve: results of the JUSTIFY-CFR Study (Joined Coronary Pressure and Flow Analysis to Determine Diagnostic Characteristics of Basal and Hyperemic Indices of Functional Lesion Severity-Coronary Flow Reserve). Circ Cardiovasc Interv 2014, 7(4):492-502.

7. Serruys PW, Chichareon P, Modolo R, Leaman DM, Reiber JHC, Emanuelsson H, Di Mario C, Pijls NHJ, Morel MA, Valgimigli M et al: The SYNTAX score on its way out or ... towards artificial intelligence: part I. EuroIntervention 2020, 16(1):44-59.

8. Warisawa T, Cook CM, Howard JP, Ahmad Y, Doi S, Nakayama M, Goto S, Yakuta Y, Karube K, Shun-Shin MJ et al: Physiological Pattern of Disease Assessed by Pressure-Wire Pullback Has an Influence on Fractional Flow Reserve/Instantaneous Wave-Free Ratio Discordance. Circ Cardiovasc Interv 2019, 12(5):e007494.

9. Stegehuis VE, Wijntjens GW, Murai T, Piek JJ, van de Hoef TP: Assessing the Haemodynamic Impact of Coronary Artery Stenoses: Intracoronary Flow Versus Pressure Measurements. Eur Cardiol 2018, 13(1):46-53. 
10. Barbato E, Aarnoudse W, Aengevaeren WR, Werner G, Klauss V, Bojara W, Herzfeld I, Oldroyd KG, Pijls NH, De Bruyne B: Validation of coronary flow reserve measurements by thermodilution in clinical practice. European Heart Journal 2004, 25(3):219-223.

11. Everaars H, de Waard GA, Driessen RS, Danad I, van de Ven PM, Raijmakers PG, Lammertsma AA, van Rossum AC, Knaapen P, van Royen N: Doppler Flow Velocity and Thermodilution to Assess Coronary Flow Reserve: A Head-to-Head Comparison With [(15)O]H(2)O PET. JACC Cardiovasc Interv 2018, 11(20):2044-2054.

12. Williams RP, de Waard GA, De Silva K, Lumley M, Asrress K, Arri S, Ellis H, Mir A, Clapp B, Chiribiri A et al: Doppler Versus Thermodilution-Derived Coronary Microvascular Resistance to Predict Coronary Microvascular Dysfunction in Patients With Acute Myocardial Infarction or Stable Angina Pectoris. Am J Cardiol 2018, 121(1):1-8.

13. Lee SH, Lee JM, Park J, Choi KH, Hwang D, Doh JH, Nam CW, Shin ES, Hoshino M, Murai T et al: Prognostic Implications of Resistive Reserve Ratio in Patients With Coronary Artery Disease. J Am Heart Assoc 2020, 9(8):e015846.

14. Gallinoro E, Colaiori I, Di Gioia G, Fournier S, Kodeboina M, Candreva A, Sonck J, Pijls NHJ, Collet C, De Bruyne B: Quantifying coronary microvascular disease: assessing absolute microvascular resistance reserve (MRR) by continuous coronary thermodilution. European Heart Journal 2020, 41(Supplement_2).

15. van de Hoef TP, de Waard GA, Meuwissen M, Voskuil M, Chamuleau SAJ, van Royen N, Piek JJ: Invasive coronary physiology: a Dutch tradition. Neth Heart J 2020, 28(Suppl 1):99-107. 
16. Härle T, Luz M, Meyer S, Kronberg K, Nickau B, Escaned J, Davies J, Elsässer A: Effect of Coronary Anatomy and Hydrostatic Pressure on Intracoronary Indices of Stenosis Severity. JACC Cardiovasc Interv 2017, 10(8):764-773.

17. Kawaguchi Y, Ito K, Kin H, Shirai Y, Okazaki A, Miyajima K, Watanabe T, Tatsuguchi M, Wakabayashi Y, Maekawa Y: Impact of Hydrostatic Pressure Variations Caused by Height Differences in Supine and Prone Positions on Fractional Flow Reserve Values in the Coronary Circulation. J Interv Cardiol 2019, 2019:4532862.

18. Üveges Á, Tar B, Jenei C, Czuriga D, Papp Z, Csanádi Z, Kőszegi Z: The impact of hydrostatic pressure on the result of physiological measurements in various coronary segments. Int J Cardiovasc Imaging 2021;37(1):5-14. doi: 10.1007/s10554-020-01971

19. Tar B, Jenei C, Dezsi CA, Bakk S, Beres Z, Santa J, Svab M, Szentes V, Polgar P, Bujaky C et al: Less invasive fractional flow reserve measurement from 3-dimensional quantitative coronary angiography and classic fluid dynamic equations. EuroIntervention 2018, 14(8):942-950.

20. Csippa B, Üveges Á, Gyürki D, Jenei C, Tar B, Bugarin-Horváth B, Szabó GT, Komócsi A, Paál G, Köszegi Z. Simplified coronary flow reserve calculations based on threedimensional coronary reconstruction and intracoronary pressure data. Cardiol J. 2021 doi: 10.5603/CJ.a2021.0117. Epub ahead of print.

21. Young DF, Cholvin NR, Roth AC: Pressure drop across artificially induced stenoses in the femoral arteries of dogs. Circ Res 1975, 36(6):735-743.

22. Morris PD, Ryan D, Morton AC, Lycett R, Lawford PV, Hose DR, Gunn JP: Virtual fractional flow reserve from coronary angiography: modeling the significance of coronary 
lesions: results from the VIRTU-1 (VIRTUal Fractional Flow Reserve From Coronary Angiography) study. JACC Cardiovasc Interv 2013, 6(2):149-157.

23. Tu S, Barbato E, Köszegi Z, Yang J, Sun Z, Holm NR, Tar B, Li Y, Rusinaru D, Wijns W et al: Fractional flow reserve calculation from 3-dimensional quantitative coronary angiography and TIMI frame count: a fast computer model to quantify the functional significance of moderately obstructed coronary arteries. JACC Cardiovasc Interv 2014, 7(7):768-777.

24. Kousera CA, Nijjer S, Torii R, Petraco R, Sen S, Foin N, Hughes AD, Francis DP, Xu XY, Davies JE: Patient-specific coronary stenoses can be modeled using a combination of OCT and flow velocities to accurately predict hyperemic pressure gradients. IEEE Trans Biomed Eng 2014, 61(6):1902-1913.

25. Ahn JM, Zimmermann FM, Johnson NP, Shin ES, Koo BK, Lee PH, Park DW, Kang SJ, Lee SW, Kim YH et al: Fractional flow reserve and pressure-bounded coronary flow reserve to predict outcomes in coronary artery disease. European Heart Journal 2017, 38(25):1980-1989.

26. Zimmermann FM, Pijls NHJ, De Bruyne B, Bech GJ, van Schaardenburgh P, Kirkeeide RL, Gould KL, Johnson NP: What can intracoronary pressure measurements tell us about flow reserve? Pressure-Bounded coronary flow reserve and example application to the randomized DEFER trial. Catheter Cardiovasc Interv 2017, 90(6):917-925.

27. Wijntjens GWM, van Lavieren MA, van de Hoef TP, Echavarría-Pinto M, Meuwissen M, Stegehuis VE, Murai T, Escaned J, Piek JJ: Pressure-derived estimations of coronary flow reserve are inferior to flow-derived coronary flow reserve as diagnostic and risk stratification tools. Int J Cardiol 2019, 279:6-11. 
28. Morris PD, Gosling R, Zwierzak I, Evans H, Aubiniere-Robb L, Czechowicz K, Evans PC, Hose DR, Lawford PV, Narracott A et al: A Novel Method for Measuring Absolute Coronary Blood Flow \& Microvascular Resistance in Patients with Ischaemic Heart Disease. Cardiovasc Res 2020.

29. Gosling RC, Sturdy J, Morris PD, Fossan FE, Hellevik LR, Lawford P, Hose DR, Gunn J: Effect of side branch flow upon physiological indices in coronary artery disease. J Biomech 2020, 103:109698.

30. Johnson NP, Oldroyd KG: Flow, pressure, anatomy: an eternal golden braid. Cardiovasc Res 2021, 117(6):1426-1427.

31. Szabó GT, Üveges Á, Tar B, Ágoston A, Dorj A, Jenei C, Kolozsvári R, Csippa B, Czuriga D, Köszegi Z. The Holistic Coronary Physiology Display: Calculation of the Flow Separation Index in Vessel-Specific Individual Flow Range during Fractional Flow Reserve Measurement Using 3D Coronary Reconstruction. J Clin Med. 2021;10(9):1910. doi: 10.3390/jcm10091910. 


\section{Figure legends}

\section{Figure 1. Calculation of CFR and MRR values during FFR measurement}

The method for calculating CFRp-3D and MRRp-3D uses haemodynamic calculations combining intracoronary pressure data (top left panel) and 3D anatomical parameters (bottom left panel). On the basis of the hyperemic and resting pressure data, as well as 3D anatomical parameters, simple haemodynamic equations were used to calculate resting and hyperemic flow, CFR and MRR. The detailed description of the flow calculations is described in the patent of the method: https://patents.google.com/patent/WO2019175612A2/en [20].

\section{Figure 2. Results of simultaneous pressure and flow measurements by the ComboWire}

In this case the average proximal (aortic) and distal pressures were detected to be $95 \mathrm{mmHg}$ and $88 \mathrm{mmHg}$, respectively. At maximal hyperemia (P), the average peak velocity (APV-P) increased to $29 \mathrm{~cm} / \mathrm{s}$ parallel with the increase in the pressure drop (the proximal and distal pressures were $89 \mathrm{mmHg}$ and $79 \mathrm{mmHg}$, respectively). The measured FFR was 0.89, while the CFR 2.9 (Case 10).

\section{Figure 3. The height difference between the LAD orifice and the sensor position}

After 3D reconstruction, the height difference between the orifice and the pressure wire sensor was transformed to $\mathrm{mmHg}$ getting hydrostatic pressure (red) (Case 10). This value (5.58 $\mathrm{mmHg}$ ) influences the gradient between the aortic pressure at the tip of the catheter and the pressure detected by the sensor of the pressure wire, and it has a great impact on the results of the CFR calculation. 
Figure 4. Correlations and agreements between calculated CFRp-3D values without and with hydrostatic offset correction, and the measured Doppler CFR values

A and B: Correlations between the calculated CFRp-3D values without and with hydrostatic offset correction and the measured Doppler CFR values: $\mathrm{r}=0.57, \mathrm{p}=0.01$ and $\mathrm{r}=0.89, \mathrm{p}<0.0001$, respectively.

C and D: Bland-Altman analysis of the agreement between the calculated CFRp-3D values without and with hydrostatic offset correction and the measured Doppler CFR values.

The mean differences between the Doppler-measured and the calculated CFR values without and with hydrostatic error correction were found to be -0.05 ( $(1$ 1.96SD: $1.38-1.48)$ and $-0.02( \pm 1.96$ SD: $0.47-0.50$ ), respectively. After hydrostatic error correction the agreement was in a narrower range (without systematic skewing) than before the correction (note the different scales of y axes generated by the statistical software between panel C and D).

Figure 5. Correlation and agreement between the results of the ComboWire based MRR measurements $\left(M R R_{C o m b o w i r e}\right)$ and the calculated $M R R_{p-3 D}$ values with the correction for hydrostatic offset

A: The calculated microvascular resistance reserve $\mathrm{MRR}_{\mathrm{p}-3 \mathrm{D}}$ demonstrated a good correlation with the measured MRR ComboWire values $(\mathrm{r}=0.58, \mathrm{p}=0.009)$.

B: The Bland-Altman analysis showed the mean differences between the Doppler-measured and the calculated $\mathrm{MRR}_{\mathrm{p}-3 \mathrm{D}}$ values with hydrostatic offset correction to be $-0.3( \pm 1.96 \mathrm{SD}: 1.5,-2.2)$ 
with a trend of greater differences at higher $M R R$ values. The $M_{R R} R_{p-3 D}$ overestimated the MRR ${ }_{\text {ComboWire values in the cases }} \mathrm{MRR}_{\mathrm{p}-3 \mathrm{D}}>5$ values.

Figure 6. Clustered multiple variable graphs of resting $P_{d} / P_{a}, F F R$ and $C F R_{p-3 D}$ without and with hydrostatic pressure correction

In both the resting and the hyperemic (FFR) state (A and $\mathbf{B})$, the correction of the hydrostatic offset resulted differences in consequent directions between the uncorrected and corrected values in the main coronary branches. The correction significantly increased the values in the LAD, while in the LC and in the RCA the values decreased. Much greater differences with the same direction can be observed for the CFRs, especially in the range of the higher values (C).

Table 1: Clinical characteristics

DM: diabetes mellitus; DVT: deep vein thrombosis; CCS: chronic coronary syndrome; PCI: percutaneous coronary intervention; PAD: peripheral artery disease

Table 2: Measured and calculated haemodynamic parameters of the interrogated lesions

* Cases No8, No13 and No19 are the same vessels as No7, No12 and No18 after stent implantation

** Hydrostatic pressure difference is the difference between the hydrostatic pressure between the pressure sensor and the tip of the catheter at the coronary orifice (hydrostatic pressure offset)

*** Corrected values are calculated with the corrected hydrostatic pressures

RCA: right coronary artery; LAD: left anterior descending coronary artery; LCX: left circumflex artery; OM: obtuse marginal branch; prox: proximal vessel segment; med: medial vessel segment; dist: distal vessel segment; $\mathrm{Pd} / \mathrm{Pa}$ : distal coronary pressure at rest / aortic pressure at rest; FFR: fractional flow reserve; CFRp-3D: coronary flow reserve calculated from intracoronary pressure 
data and 3D anatomical parameters; APV: average peak velocity at rest or during vasodilatation (vd) measured by Doppler wire; CFRDoppler: coronary flow reserve measured by Doppler wire; MRRp-3D:microvascular reserve ratio calculated from intracoronary pressure data and 3D anatomical parameters; MRRDoppler: microvascular reserve ratio measured by Doppler wire. 


\section{Figure 1.}

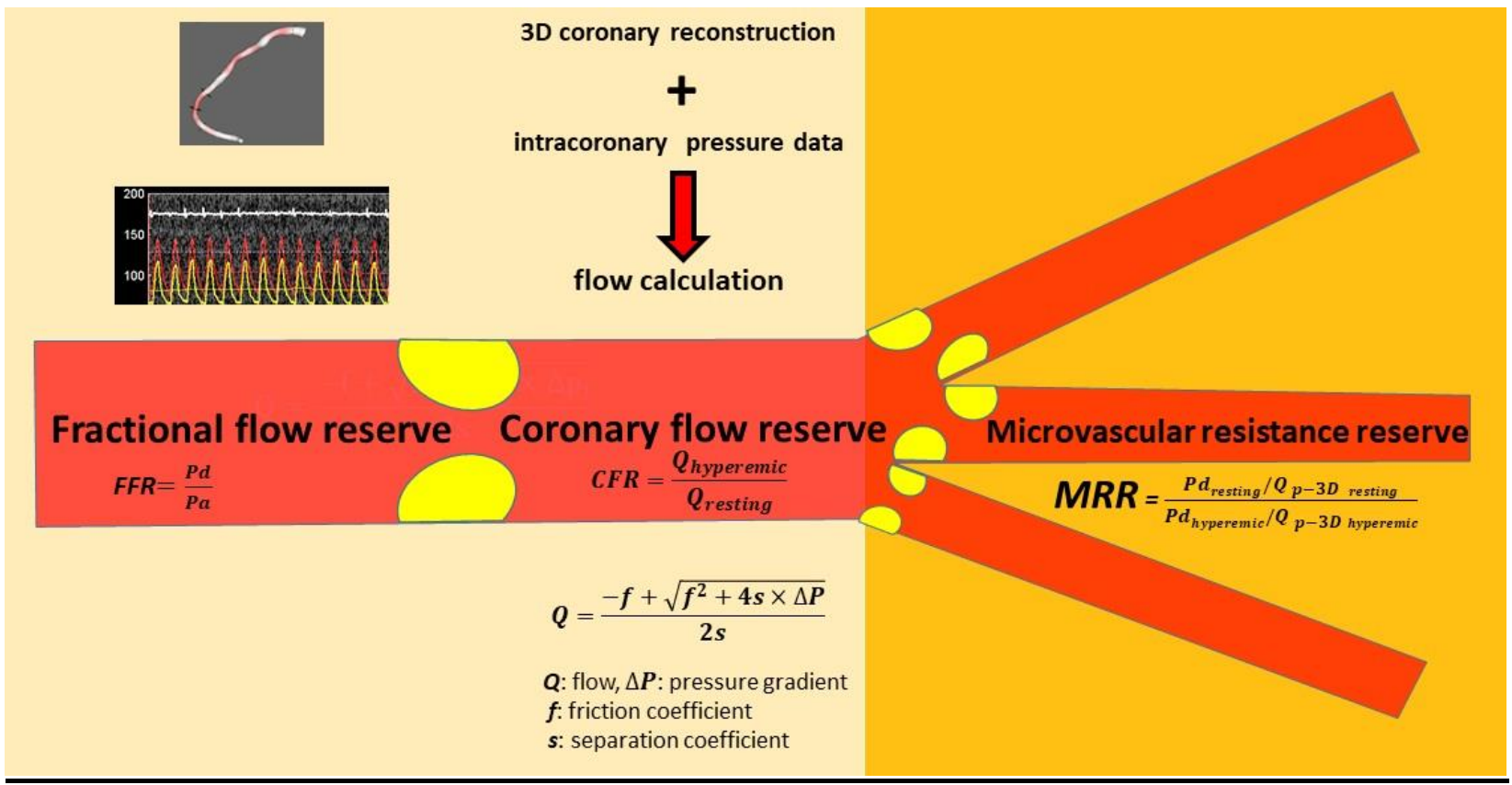

Figure 2.

B P

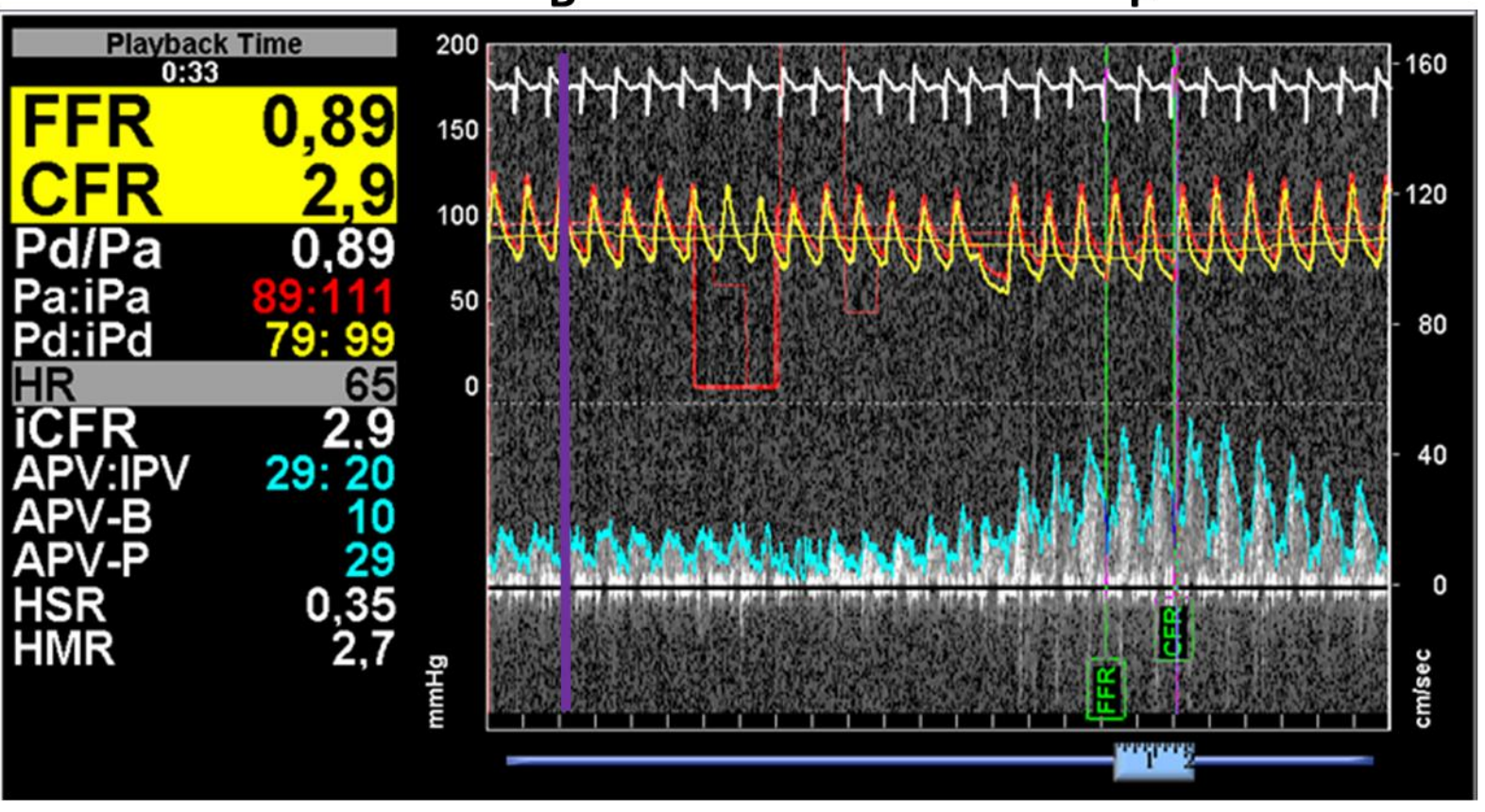




\section{Figure 3.}

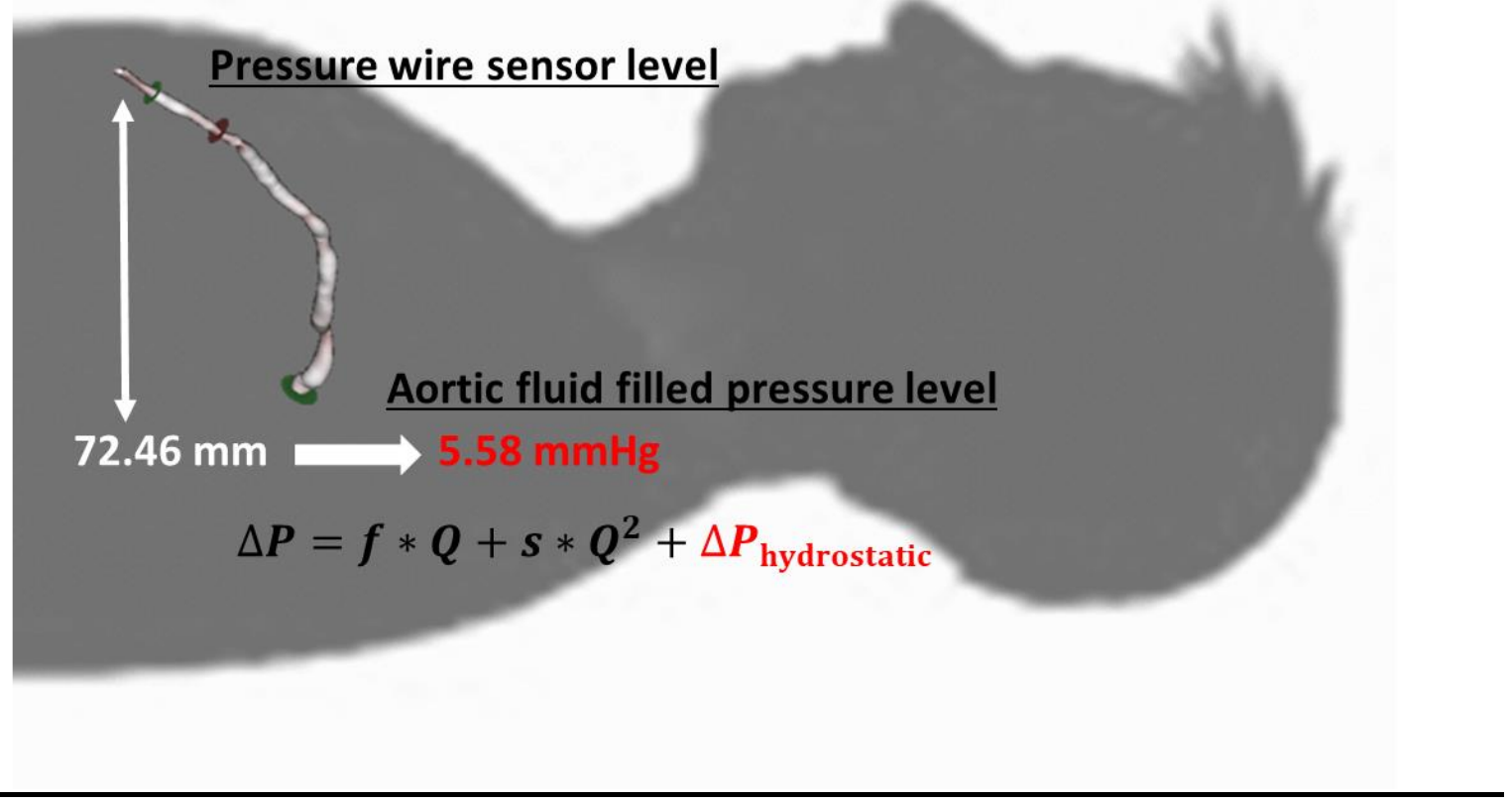

\section{Figure 4.}
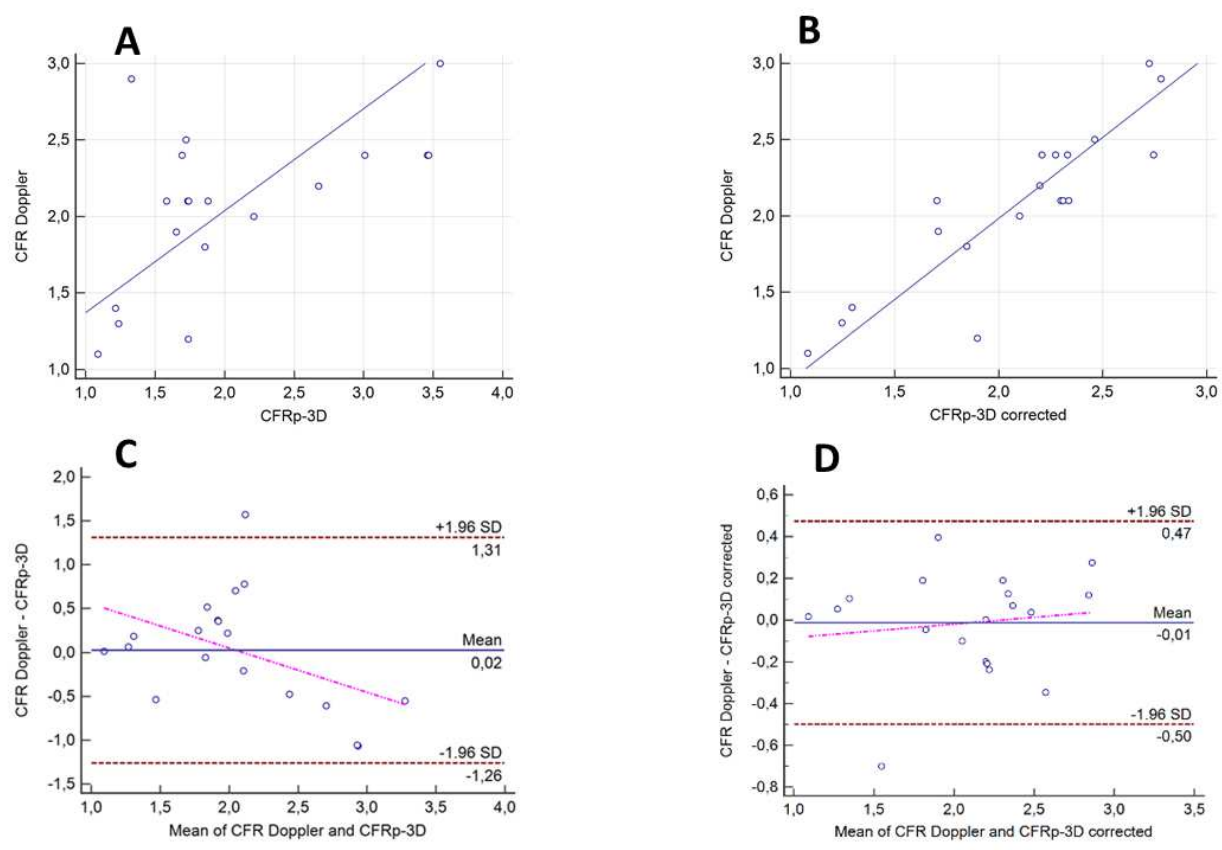


\section{Figure 5.}
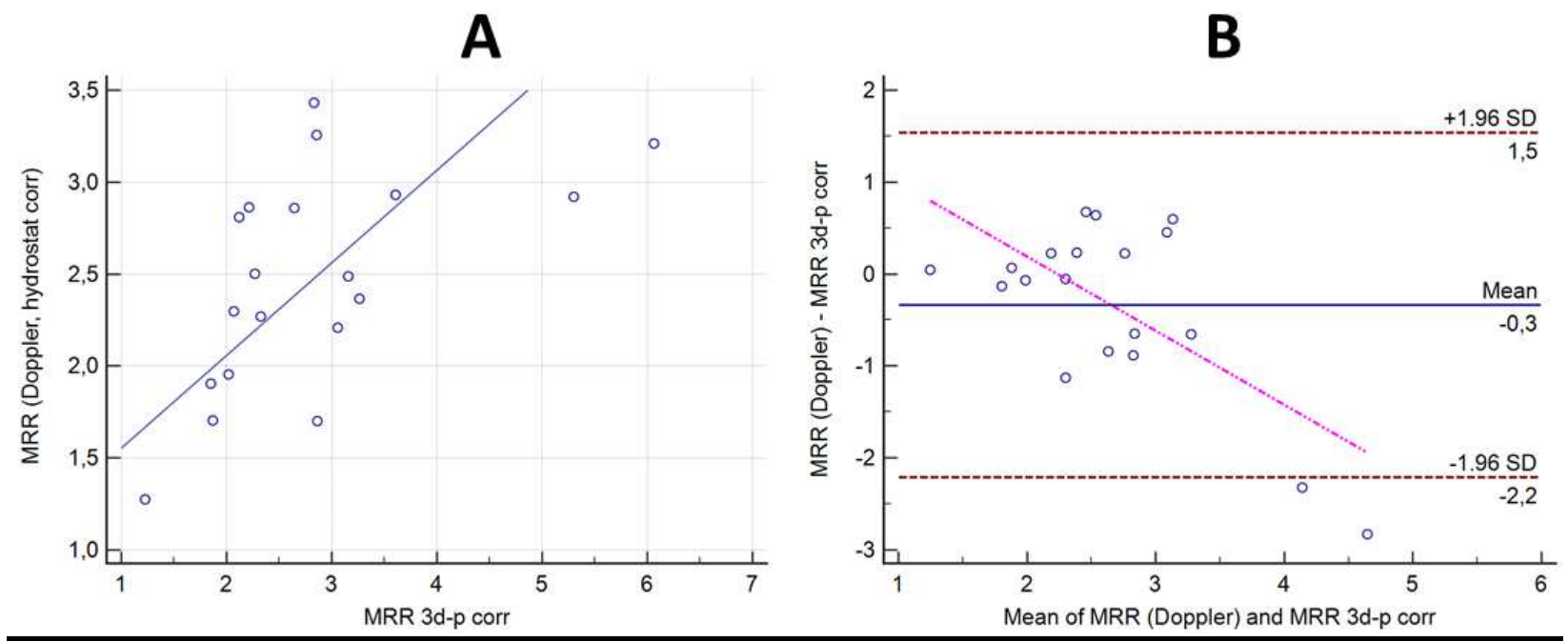

Figure 6.

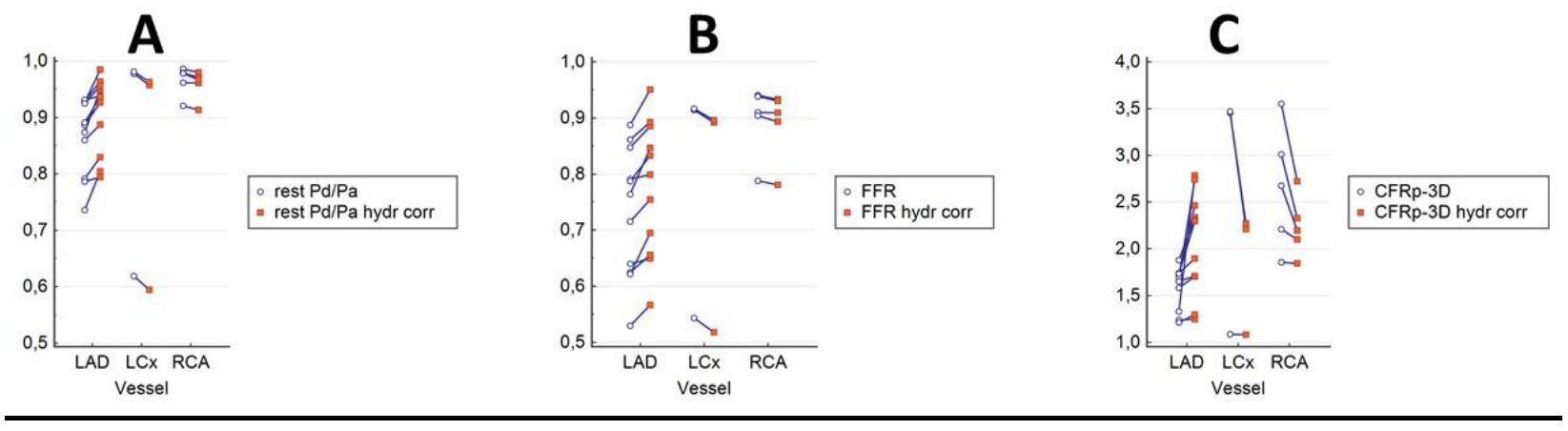


Table 1: Clinical characteristics

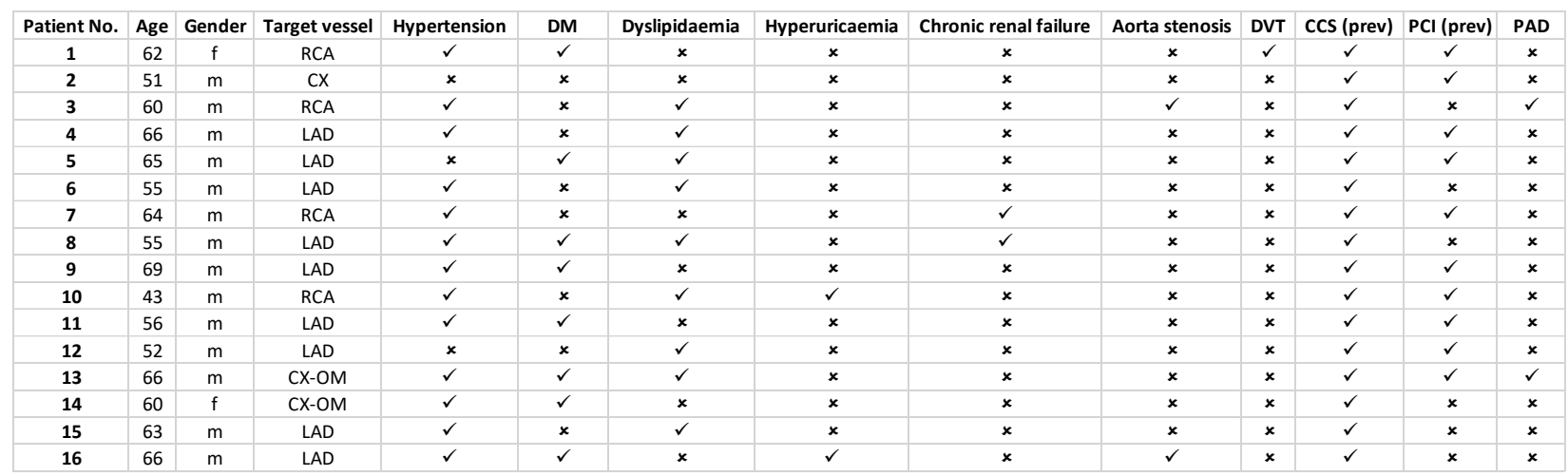

Table 2: Measured and calculated hemodynamic parameters of the interrogated lesions

\begin{tabular}{|c|c|c|c|c|c|c|c|c|c|c|c|}
\hline $\begin{array}{c}\text { Case } \\
\text { No }\end{array}$ & $\begin{array}{c}\text { Vessel } \\
\text { segment }\end{array}$ & $\begin{array}{l}\text { Hydrostatic } \\
\text { pressure } \\
\text { difference } \\
(\mathrm{mmHg})^{* *}\end{array}$ & $\mathrm{Pd} / \mathrm{Pa}_{\text {rest }}$ & FFR & CFR $_{\mathrm{p}-3 \mathrm{D}}$ & $\begin{array}{c}\mathrm{CFR}_{\mathrm{p}-3 \mathrm{D}} \\
\text { corrected } \\
* * *\end{array}$ & $\begin{array}{l}A P V_{\text {rest }} \\
(\mathrm{cm} / \mathrm{s})\end{array}$ & $\begin{array}{l}A P V_{v d} \\
(\mathrm{~cm} / \mathrm{s})\end{array}$ & $\begin{array}{c}\text { CFR } \\
\text { Doppler }\end{array}$ & $\begin{array}{c}\mathrm{MRR}_{\mathrm{p}-3 \mathrm{D}} \\
\text { corrected } \\
* * *\end{array}$ & $\begin{array}{l}\text { MRR }_{\text {Doppler }} \\
\text { corrected } \\
\quad * * *\end{array}$ \\
\hline 1 & RCA med & 0,46 & 0,99 & 0,94 & 3,55 & 2,72 & 14 & 42 & 3 & 2,83 & 3,43 \\
\hline 2 & LCx dist & 1,99 & 0,98 & 0,92 & 3,47 & 2,21 & 19 & 45 & 2,4 & 2,21 & 2,86 \\
\hline 3 & RCA med & 0,05 & 0,96 & 0,91 & 1,86 & 1,85 & 18 & 32 & 1,8 & 2,02 & 1,95 \\
\hline 4 & LAD prox & $-2,93$ & 0,92 & 0,86 & 1,74 & 2,30 & 24 & 50 & 2,1 & 3,05 & 2,21 \\
\hline 5 & LAD med & $-2,50$ & 0,86 & 0,63 & 1,58 & 1,70 & 14 & 29 & 2,1 & 2,86 & 3,26 \\
\hline 6 & LAD prox & $-0,69$ & 0,79 & 0,64 & 1,24 & 1,25 & 32 & 42 & 1,3 & 1,85 & 1,91 \\
\hline 7* & RCA med & 0,76 & 0,92 & 0,79 & 2,21 & 2,10 & 15 & 30 & 2 & 2,32 & 2,27 \\
\hline 8 & $\begin{array}{l}\text { RCA med } \\
\text { (post stent) }\end{array}$ & 0,77 & 0,98 & 0,94 & 2,68 & 2,20 & 15 & 33 & 2,2 & 2,07 & 2,30 \\
\hline 9 & LAD prox & $-0,71$ & 0,93 & 0,79 & 1,65 & 1,71 & 19 & 36 & 1,9 & 2,64 & 2,86 \\
\hline 10 & LAD med & $-5,58$ & 0,93 & 0,89 & 1,33 & 2,78 & 10 & 29 & 2,9 & 6,06 & 3,21 \\
\hline 11 & RCA med & 1,05 & 0,98 & 0,90 & 3,01 & 2,33 & 36 & 86 & 2,4 & 2,27 & 2,50 \\
\hline $12 *$ & LAD dist & $-4,51$ & 0,89 & 0,72 & 1,88 & 2,34 & 22 & 45 & 2,1 & 3,16 & 2,49 \\
\hline 13 & $\begin{array}{l}\text { LAD dist } \\
\text { (post stent) }\end{array}$ & $-3,93$ & 0,93 & 0,85 & 1,72 & 2,46 & 22 & 55 & 2,5 & 3,60 & 2,93 \\
\hline 14 & LAD prox & $-3,65$ & 0,79 & 0,53 & 1,74 & 1,90 & 38 & 46 & 1,2 & 2,86 & 1,70 \\
\hline 15 & $\begin{array}{c}\text { LCx dist } \\
\text { (OM) }\end{array}$ & 2,60 & 0,62 & 0,54 & 1,09 & 1,08 & 33 & 36 & 1,1 & 1,22 & 1,27 \\
\hline 16 & $\begin{array}{c}\text { LCx dist } \\
\text { (OM) }\end{array}$ & 1,84 & 0,98 & 0,91 & 3,46 & 2,27 & 26 & 62 & 2,4 & 2,12 & 2,81 \\
\hline 17 & LAD prox & $-5,00$ & 0,89 & 0,79 & 1,74 & 2,31 & 15 & 31 & 2,1 & 3,26 & 2,37 \\
\hline $18^{*}$ & LAD med & $-6,00$ & 0,74 & 0,62 & 1,21 & 1,30 & 31 & 43 & 1,4 & 1,87 & 1,70 \\
\hline 19 & $\begin{array}{l}\text { LAD med } \\
\text { (post stent) }\end{array}$ & $-6,00$ & 0,87 & 0,76 & 1,69 & 2,74 & 24 & 57 & 2,4 & 5,30 & 2,92 \\
\hline
\end{tabular}

